\title{
Vibration Isolation on Tractor Seat Through Rubber-Pad
}

\author{
Kavad Anil $^{1 *}$, Hapani Mitanshu ${ }^{2}$, M.D. Vora ${ }^{2}$ and R. Yadav ${ }^{1}$ \\ ${ }^{1}$ Junagadh Agril University, Junagadh, India \\ ${ }^{2}$ CAET, AAU Godhra, India \\ *Corresponding author
}

\section{A B S T R A C T}

\section{Keywords}

Vibration, Vibration isolation pad, Acceleration, Mini tractor

Article Info

Accepted:

22 January 2019

Available Online:

10 February 2019
This study examines the vibrations produced by mini tractor under different vibration isolation pad at different speed. A digital vibration meter VB-08201HA was used to measure vibrations generated by mini tractor. The vibration levels of tractor on plane surface of seat resting plate in $\mathrm{X}, \mathrm{Y}$, and $\mathrm{Z}$ directions were measured in acceleration $\left(\mathrm{m} / \mathrm{s}^{2}\right)$ at 1250,1500 and $1750 \mathrm{rpm}$ of tractor with the use of Thick ribbed natural rubber isolation pad (T-1), Thin ribbed natural rubber isolation pad (T-2), cork pad (T-3), thin ribbed natural rubber isolation pad with neoprene rubber sheet (T-4) and without anti vibration rubber pad (T-5). As per results, minimal level of vibration in longitudinal direction (2.49 $\mathrm{m} / \mathrm{s} 2$ ) was found by the use of thin ribbed natural rubber isolation pad with neoprene sheet. In lateral direction, maximum vibration reduction was found under thick ribbed natural rubber isolation pad $\left(2.93 \mathrm{~m} / \mathrm{s}^{2}\right)$. In vertical direction, minimum levels of vibration were found under cork pad $\left(6.52 \mathrm{~m} / \mathrm{s}^{2}\right)$. As per review of literature vertical vibrations are most sensitive to the operator. Therefore use of the cork pad for control of the vibration in the tractor seat is recommended.

\section{Introduction}

An agricultural tractor is exposed to vibration caused by moving engine elements, and unevenness of soil profile. The effects of vibration on the health of tractor operator on the basis of frequency up to $2 \mathrm{~Hz}$ causing discomfort problems, such as: exhaustion, headache, nausea, vomiting, inability, weakening, and vertigo. Studies have also shown degeneration of the lumbar spine with long-term exposure to whole-body vibration (Tiemessen et al., 2011) stated that tractor operators are subject to vibration in all three directions, but they can endure more severe vibration in the longitudinal and transverse direction than in the vertical direction. Vibrations primarily are of two types: sinusoidal and random. Sinusoidal vibration is the regular in nature and predictable. Random vibration is irregular and unpredictable.

The experiment was conducted to study the capability of different vibration isolation pads to mitigate the severity of tractor seat vibrations. For that, four different kinds of rubber isolation pads were utilized along with no mounting of pad. Observations of vibration levels in the terms of acceleration $\left(\mathrm{m} / \mathrm{s}^{2}\right)$ were recorded at different RPM viz. 1250, 1500 
and 1750 RPM. The result in respect of the performance of pads in reducing the vibration levels in three directions at different RPM

\section{Review of literature}

Investigation of Janeway (1975) revealed that the predominant vibration motion of a wheeltractor is vertical and that the operator is most sensitive to this vibration. The effect of longitudinal and transverse modes depends on the type of task being performed by the tractor.

The efficiency and speed of agricultural tractors has increased so that vibrations are higher, and tractors often contain high power sources which create new vibration problems (Servadio et al., 2007).

McLauchlan, (2006) stated that in most considerations of vibration problems we deal with one of three possible parameters for vibration measurement. The first is displacement and the other two are velocity and acceleration.

Cvetanovic et al., (2013) have studied the level of whole body vibration and found that tractor drivers are exposed to vibration to negative influences that leads the health related problems.

Dupuis and Christ et al., (1966) reported two forms of health problems which were clearly demonstrated to result from long periods of tractor operation: stomach complaints and disorders of the spine, the percentage of tractor drivers with spinal deformations increased from 72.5 to $78.9 \%$.

Petrovich et al., (2005) stated that Multiplied vibration levels that occur in a complex system such as tractor are transmitted to the operator in three basic ways through the seat, when whole body vibration of the operator is induced.
Goglia et al., (2006) mentioned that the operators of agricultural tractors are exposed to whole body vibrations and shocks. Whole body vibrations are usually transmitted via the seat, the floor and feet, and hand arm.

Vibration influence at frequencies from 2 to $80 \mathrm{~Hz}$ causing: skeleton alterations, digestive system disorders, changes in the urinary and genetic system (Zehsaz et al., 2011).

Matthews (1973) stated that performing tasks that require steadiness or precision of muscular control is likely to show decrement from vibration. He pointed out that vibration between 3.5 and $6.0 \mathrm{~Hz}$ can have an alerting effect on subjects engaged in boring vigilance tasks.

Tendon and Nakra (1992) stated that vibration in the time domain can be measured through parameter such as overall RMS level, crest factor, probability density and kurtosis. Among these, kurtosis is the most effective.

Seidel (1993) indicated that Long-term whole-body vibration exposure can probably contribute to the pathogenesis of disorders of female reproductive organs (menstrual disturbances, anomalies of position) and disturbances of pregnancy (abortions, stillbirths).

Rottensteiner et al., (2013) used the analysis of variance (ANOVA) module of the software package PASW Statistics 18 for comparison of the vibration and noise data during the various operational modes and configurations and for examining the effect of the chipper model, the setup-type, and wood material, on the operator's exposure to vibration and noise.

\section{Materials and Methods}

Selection of Tractors: One tractor (Fig. 1) selected from College of Agricultural Engineering and Technology (CAET) of 
Anand Agricultural University (AAU) was used for the purpose of vibration testing at different engines speed (RPM) and different rubber-pad.

Units of Vibration Measurement: Measurement of vibration levels was conducted by recording velocity and acceleration in $\mathrm{mm} / \mathrm{s}$ and $\mathrm{m} / \mathrm{s}^{2}$ respectively.

Use of Digital Vibration Meter: Vibration meter is used to measure the vibration levels in the units of acceleration and velocity. The Vibration meter VB-8201HA available at the FMPE laboratory was used to measure the different Vibration levels.

Vibration Measurement on Tractors: The vibration level observations were recorded in three directions i.e. horizontal front to rear (X) direction, horizontal side to side $(\mathrm{Y})$ direction and vertical top to bottom (Z) direction (Fig. 7). Observations were taken at different engine speeds with different vibration isolated-pad. viz. 1250, 1500 and 1750 RPM at seat bottom on the tractor in standstill condition.

Use of Rubber Pad and Rubber Sheet: Thick ribbed natural rubber pad, Thin ribbed natural rubber pad, cork pad and Thin ribbed natural rubber pad with neoprene rubber sheet were used for mounting below the seat on Tractor-1 (Captain) with a view to reduce the intensity of vibration levels (Fig. 2-8).

\section{Results and Discussion}

The graphs indicate that Measurement of Vibration at 1250 RPM tractor engine speed: At 1250 RPM, the average values of acceleration $\left(\mathrm{m} / \mathrm{s}^{2}\right)$ in thick ribbed natural rubber pad, thin ribbed natural rubber pad, cork pad, thin ribbed natural rubber pad with neoprene rubber sheet and in without pad in longitudinal direction are found to be 2.44 , $3.19,2.65,1.89$ and $5.83 \mathrm{~m} / \mathrm{s}^{2}$ respectively.
Similarly lateral direction are found to be $2.99, \quad 2.53, \quad 5.41, \quad 3.61$ and 5.50 $\mathrm{m} / \mathrm{s}^{2}$ respectively, and Vertical direction are found to be 6.10, 6.54, 4.96, 5.98 and 11.15 $\mathrm{m} / \mathrm{s}^{2}$ respectively.

The graphs indicate that Measurement of Vibration at 1500 RPM tractor engine speed: At 1500RPM, the average values of acceleration $\left(\mathrm{m} / \mathrm{s}^{2}\right)$ in thick natural rubber pad, thin ribbed natural rubber pad, cork pad, thin natural rubber pad with neoprene rubber sheet and without pad in longitudinal direction are found to be 3.38, 3.30, 3.98, 3.79 and $5.18 \mathrm{~m} / \mathrm{s}^{2}$ respectively. Similarly lateral direction are found to be $2.64,5.28,4.54$, 2.76 , and $5.36 \mathrm{~m} / \mathrm{s}^{2}$ respectively, and vertical direction are found to be 7.31, 9.46, 9.05, 8.11 and $14.68 \mathrm{~m} / \mathrm{s}^{2}$ respectively.

The graphs indicate that Measurement of Vibration at 1750 RPM tractor engine speed: At 1750RPM, the average values of acceleration $\left(\mathrm{m} / \mathrm{s}^{2}\right)$ in thick ribbed natural rubber pad, thin ribbed natural rubber pad, cork pad, thin ribbed natural rubber pad with neoprene rubber sheet and without pad in longitudinal direction are found to be 3.40 , $4.29,2.76,2.79$ and $4.76 \mathrm{~m} / \mathrm{s}^{2}$ respectively.

Similarly Lateral direction are found to be $3.13,3.53,3.11,3.51,7.53 \mathrm{~m} / \mathrm{s}^{2}$ respectively, and vertical direction are found to be 8.24 , $7.99,5.55,7.03$ and $15.94 \mathrm{~m} / \mathrm{s}^{2}$ respectively.

Comparison of the effects of different vibration isolation pads

From the below table 1 found that Percent (\%) reduction in longitudinal direction due to application of vibration pads: - The reading indicate that maximum reduction of vibration as compare to without pad in percentage on seat were observed at 1250, 1500 and 1750 RPM in thin ribbed natural rubber isolation pad with neoprene rubber sheet $(67.6 \%)$, thin 
ribbed natural rubber isolation pad with neoprene rubber sheet $(46.1 \%)$ and cork pad $(51.7 \%)$ respectively in longitudinal condition.

From the below table 2 found that per cent (\%) reduction in lateral direction due to application of vibration pads: - The reading indicate that maximum reduction of vibration as compare to without pad in percentage on seat were observed at 1250, 1500 and 1750 RPM in thick ribbed natural rubber isolation pad $(61.82 \%)$, thick ribbed natural rubber isolation pad (50.75\%) and cork pad (58.70\%) respectively in lateral condition.

From the below table 3 found that per cent (\%) reduction in vertical direction due to application of vibration pads: The reading indicate that maximum reduction of vibration as compare to without pad in percentage on seat were observed at 1250,1500 and 1750 RPM in cork pad $(55.52 \%)$, thick ribbed natural rubber isolation pad $(50.20 \%)$ and cork pad $(65.18 \%)$ respectively in vertical condition.

Table.1 Percent (\%) reduction in longitudinal direction due to application of vibration pads

\begin{tabular}{|l|l|l|l|l|}
\hline RPM & Thick pad & Thin pad & Cork pad & $\begin{array}{l}\text { Thin pad with } \\
\text { rubber sheet }\end{array}$ \\
\hline 1250 & 58.1 & 45.3 & 54.5 & $\mathbf{6 7 . 6}$ \\
\hline 1500 & 34.7 & 36.3 & 23.2 & $\mathbf{4 6 . 1}$ \\
\hline 1750 & 28.6 & 9.9 & $\mathbf{4 2}$ & 41.4 \\
\hline Average & 40.5 & 30.5 & 39.9 & $\mathbf{5 1 . 7}$ \\
\hline
\end{tabular}

Table.2 Percent (\%) reduction in lateral direction due to application of vibration pads

\begin{tabular}{|l|l|l|l|l|}
\hline RPM & Thick pad & Thin pad & Cork pad & $\begin{array}{l}\text { Thin pad with } \\
\text { rubber sheet }\end{array}$ \\
\hline 1250 & $\mathbf{6 1 . 8 2}$ & 54.00 & 1.64 & 34.36 \\
\hline 1500 & $\mathbf{5 0 . 7 5}$ & 1.49 & 15.30 & 48.51 \\
\hline 1750 & 58.43 & 53.12 & $\mathbf{5 8 . 7 0}$ & 53.39 \\
\hline Average & $\mathbf{5 7 . 0}$ & 53.1 & 25.2 & 45.4 \\
\hline
\end{tabular}

Table.3 Percent (\%) reduction in vertical direction due to application of vibration pads

\begin{tabular}{|l|l|l|l|l|}
\hline RPM & Thick pad & Thin pad & Cork pad & $\begin{array}{l}\text { Thin pad with } \\
\text { rubber sheet }\end{array}$ \\
\hline 1250 & 45.29 & 41.35 & $\mathbf{5 5 . 5 2}$ & 46.37 \\
\hline 1500 & $\mathbf{5 0 . 2 0}$ & 35.56 & 38.35 & 44.75 \\
\hline 1750 & 47.99 & 49.87 & $\mathbf{6 5 . 1 8}$ & 55.90 \\
\hline Average & 47.8 & 42.3 & $\mathbf{5 3 . 0}$ & 49.0 \\
\hline
\end{tabular}


Fig.1 Tractor model Captain DI 2600

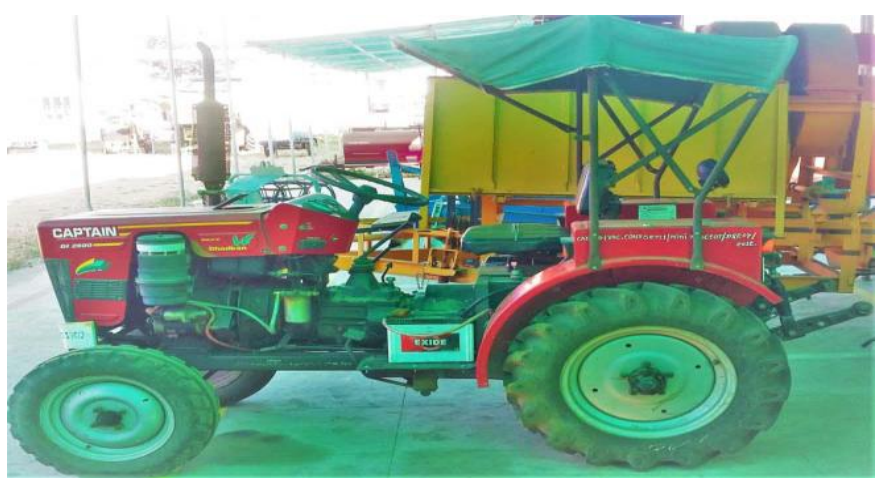

Fig.2 Position of different vibration isolation pad

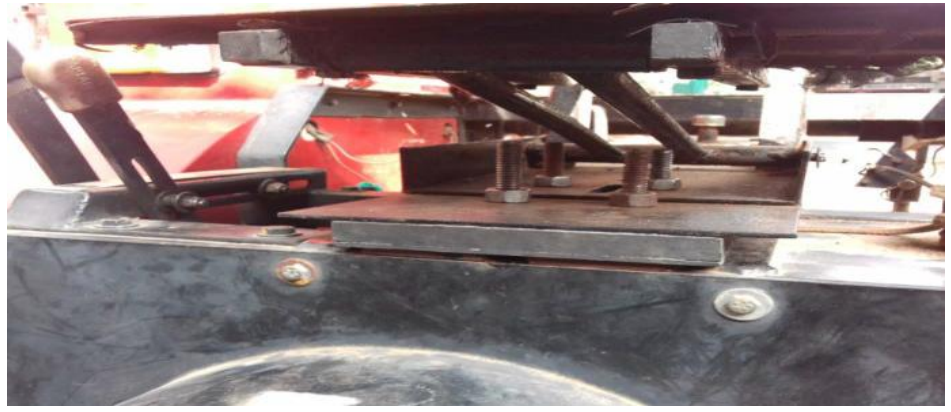

Fig.3 Thick ribbed natural rubber pad

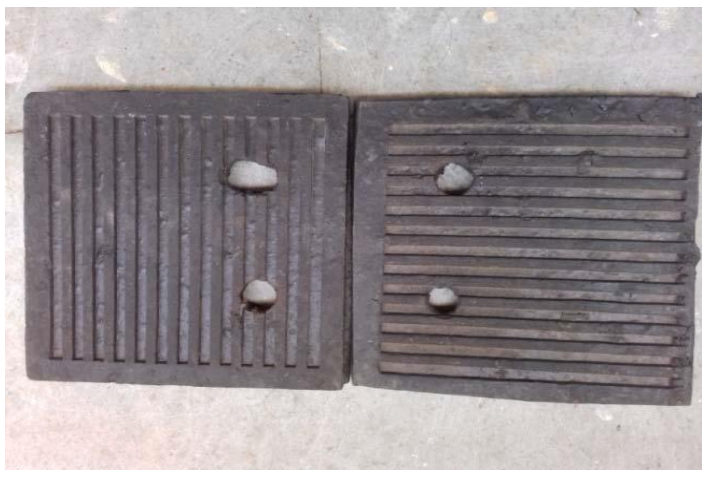

Fig.4 Thin ribbed natural rubber pad

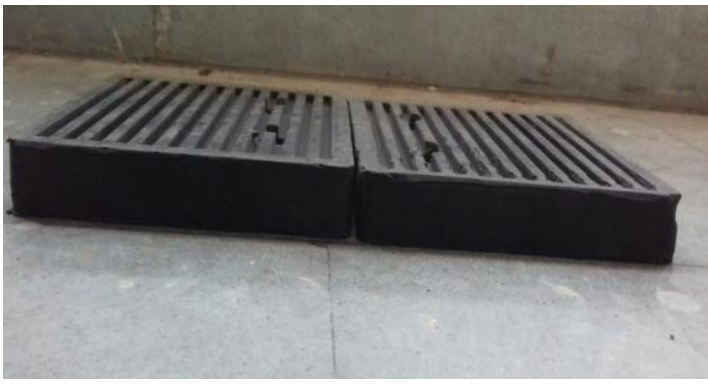


Fig.5 Cork rubber pad

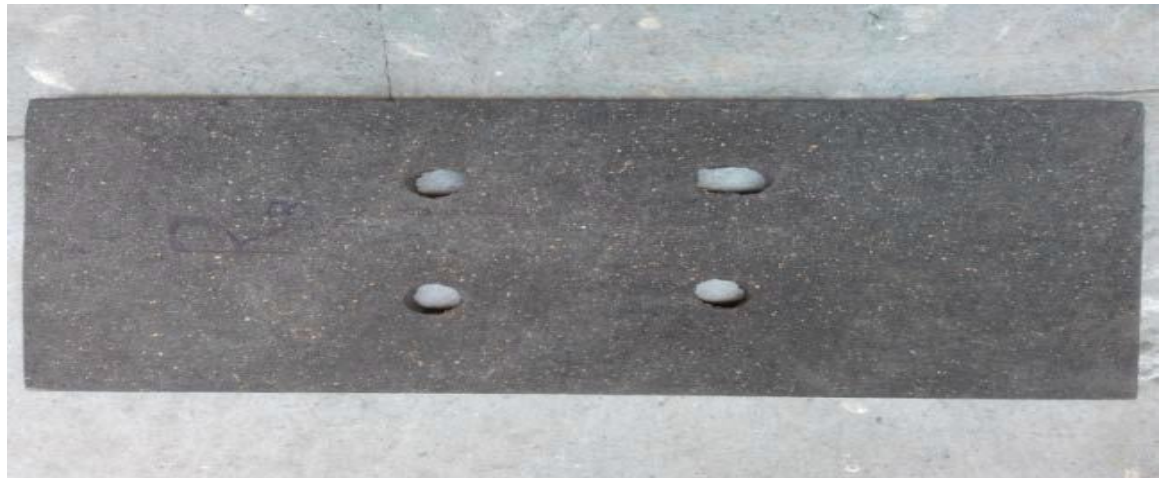

Fig.6 Bottom and top view of thin ribbed natural rubber pad with neoprene rubber sheet
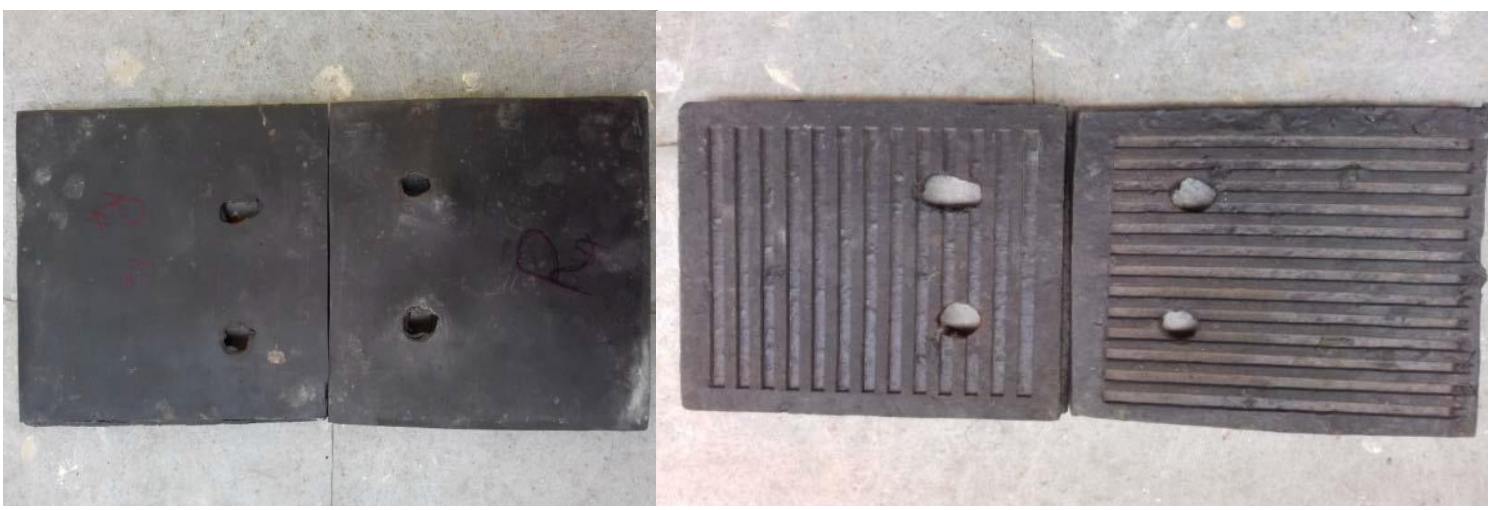

Fig.7 Vibration levels recorded on operator's seat (seat resting plate) under five different vibration isolated rubber-pad in longitudinal, lateral, and vertical direction at 1250 RPM

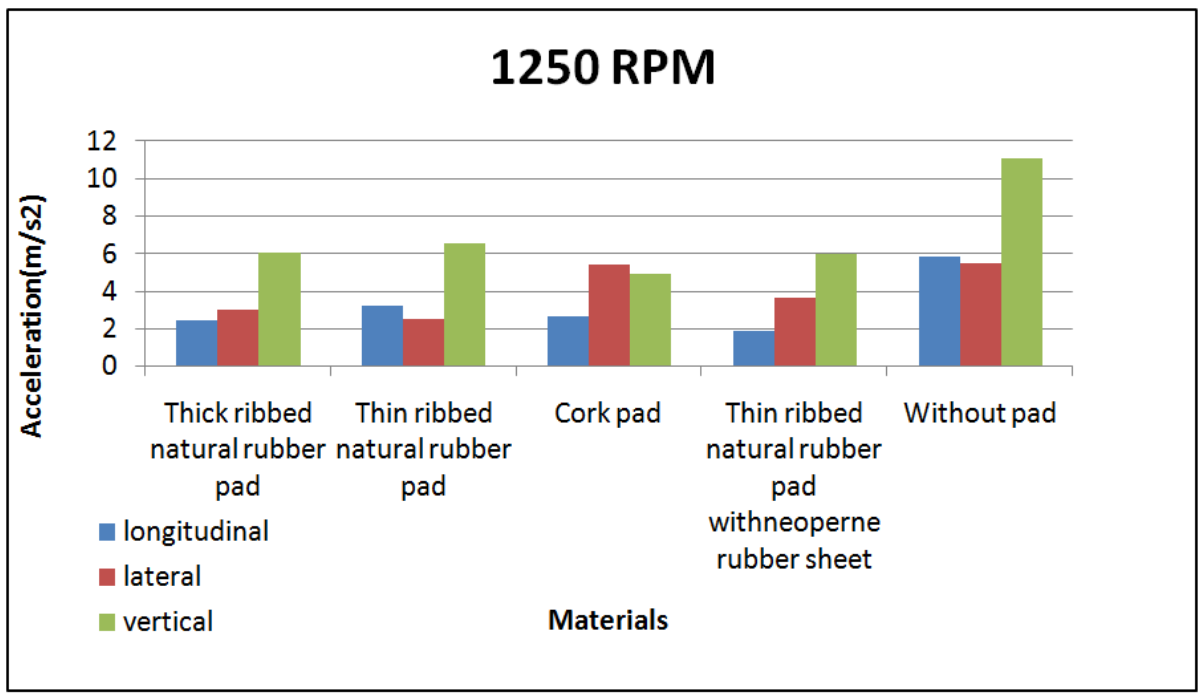


Fig.8 Vibration levels recorded on operator's seat (seat resting plate) under five different vibration isolated rubber-pad in longitudinal, lateral, and vertical direction at 1500 RPM

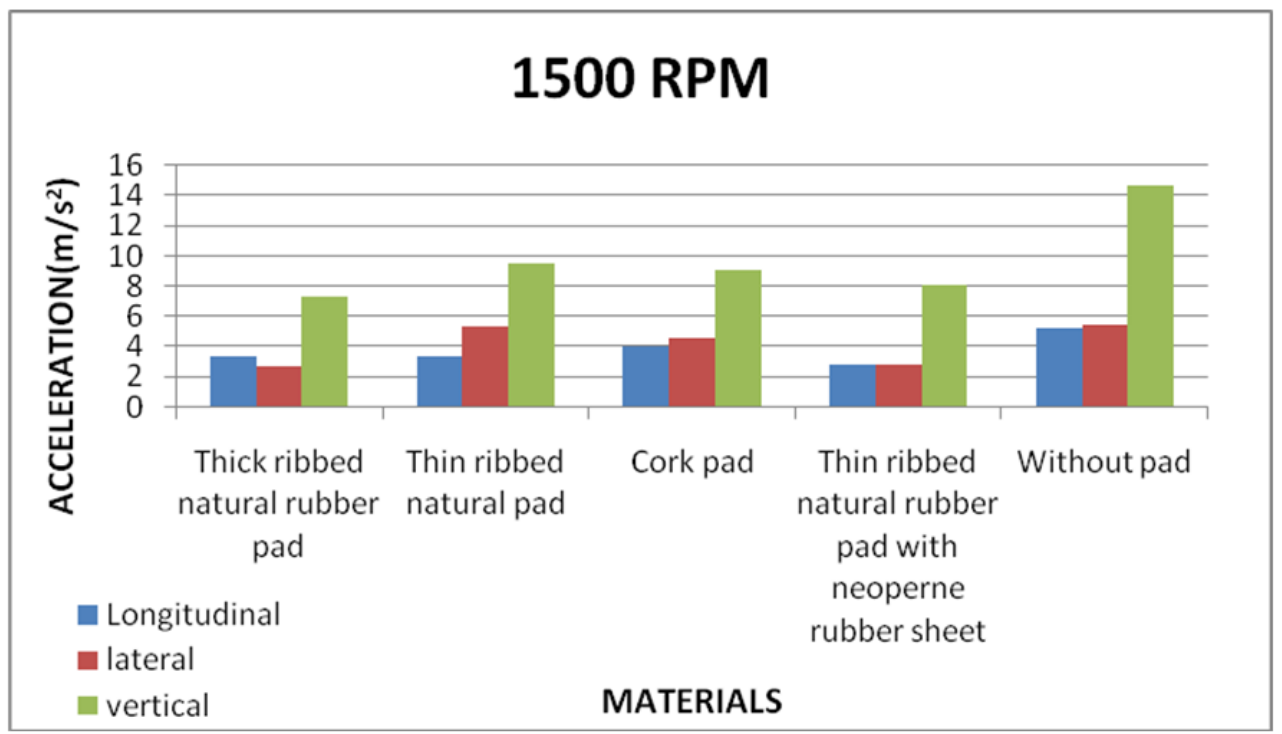

Fig.9 Vibration levels recorded on operator's seat (seat resting plate) under five different vibration isolated rubber-pad in longitudinal, lateral, and vertical direction at 1250 RPM

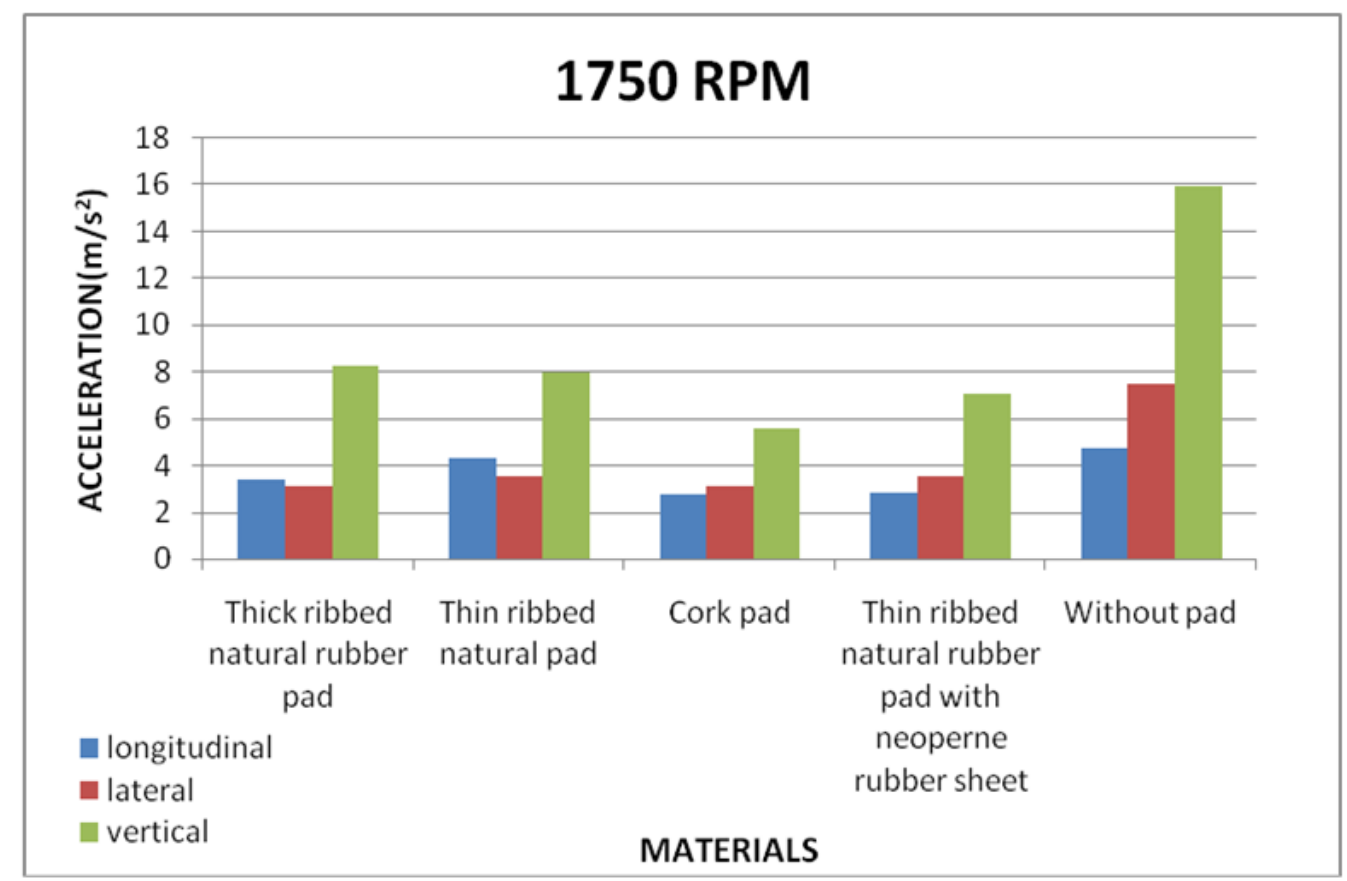

In longitudinal direction, maximum reduction in the vibration levels could be achieved under thin pad with rubber sheet. In lateral direction, maximum vibration reduction could be achieved under thick pad. In vertical direction, maximum reduction in the vibration levels could be achieved under cork pad. As found in the literature, vertical vibration 
levels are more harmful as compared to longitudinal and lateral vibrations. Therefore, use of cork pad is recommended.

\section{References}

Cvetanovic B. and Zlatkovic D. 2013. Evaluation of whole body vibration risk in agricultural tractor drivers. Bulgarian Journal of Agricultural Science, 19(5): 1155-1160.

Goglia, V., Gospodaric, Z., Filipovic, D. and Djukic, I. 2006. Influence on operator's health of hand-transmitted vibrations from handles of a singleaxle tractor. Annals of Agricultural and Environmental Medicine, 13(1): 33-38.

H. Dupuis and W. Christ. 1966. Study of the risk of spinal damage to tractor drivers. Report, Max Planck Institute Ftir Landarbeiter, land tech., Bad Kreuznach.

ISO. 1985. Guide for the evaluation of human exposure to whole body vibration. Standard 2631, International Organization for Standardization.

J. Matthews. (1973). The measurement of tractor ride comfort. SAE Paper 730795.

Rottensteiner, C., Tsioras, P., Neumayer, H. and Stampfer, K. (2013). Vibration and noise assessment of tractor-trailer and truck-mounted chippers. Silva Fennica, 47(5):14.

Scarlett, A.J., Price, J.S., and Stayner R.M.2007. Whole-body vibration: Evaluation of emission and exposure levels arising from agricultural tractors. Journal of Terramechanics, 44(1): 65-73.

Seidel H. (1993), "Selected health risks caused by long-term, whole-body vibration", Am J Ind Med. 23(4):589604.

Smets M.P., Eger T.R. and Grenier S.G. 2010. Whole-body vibration experienced by haulage truck operators in surface mining operations: a comparison of various analysis methods utilized in the prediction of health risks., Applied Ergonomics, 41(6): 763-70.

Tandon and Nakra. (1992). A review of vibration and acoustic measurement methods for the detection of defects in rolling element bearings. Tribology international, 32(8):469-480.

Tiemessen, I.J., Hulshof, C.T.J., and FringsDresen, M.H.W. 2007. An overview of strategies to reduce whole-body vibration exposure on drivers: A systematic review. International Journal of Industrial Ergonomics, 37(3): 245-256.

\section{How to cite this article:}

Kavad Anil, Hapani Mitanshu, M.D. Vora and Yadav, R. 2019. Vibration Isolation on Tractor Seat Through Rubber-Pad. Int.J.Curr.Microbiol.App.Sci. 8(02): 3141-3148. doi: https://doi.org/10.20546/ijcmas.2019.802.367 